\title{
Preparedness for COVID-19 by Primary Healthcare Workers in Rivers State, Nigeria: Facility Cross- sectional Survey
}

\section{Dr. Clement Kevin Edet}

Primary Rivers State Health Care Board, Port Harcourt, Nigeria

\section{Dr. Anthony lke Wegbom ( $\nabla$ wegbomanthony@gmail.com )}

Rivers State University, Port Harcourt, Nigeria, and Captain Elechi Amadi Polytechnic, Port Harcourt, Nigeria https://orcid.org/0000-0001-5589-7714

\section{Prof. Victor Alangibi Kiri}

Northumbria University, Newcastle upon Tyne, United Kingdom and University of Port Harcourt, Choba, Nigeria

\section{Research Article}

Keywords: Preparedness, KAP, primary healthcare workers, COVID-19, Rivers State, Nigeria

Posted Date: August 3rd, 2020

DOl: https://doi.org/10.21203/rs.3.rs-51606/v1

License: (c) (i) This work is licensed under a Creative Commons Attribution 4.0 International License. Read Full License

Version of Record: A version of this preprint was published at International Journal of TROPICAL DISEASE \& Health on September 23rd, 2020. See the published version at https://doi.org/10.9734/ijtdh/2020/v41i1330347. 


\section{Abstract}

Introduction: The primary healthcare workers (PHCWs) face a higher risk of infection associated with their occupation, due to inadequate supplies of personal protective equipment (PPE), inappropriate use of PPEs, and insufficient knowledge on infection prevention and control. Therefore, this study aimed to assess the preparedness for COVID-19 by PHCWs in Rivers State, Nigeria.

Method: A cross-sectional survey was conducted involving the healthcare workers at the public primary healthcare facilities across the 23 local government areas (LGAs) of Rivers State, Nigeria. The descriptive statistics of mean \pm standard deviation and percentage were used to present quantitative and categorical variables respectively. The preparedness for COVID-19 was measured by knowledge, attitude and preventive practices (KAP) towards the disease. The association between the KAP and demographic characteristics was tested with the Chi-square test, while the associations existing among the KAP constituents were evaluated with the Pearson correlation coefficient. Statistical significance was evaluated at $\mathrm{P}<0.05$.

Results: Out of 460 questionnaires distributed, 412 respondents participated in the survey, indicating a response rate of $89.6 \%$. The proportion of respondents with good scores in knowledge, attitude, and COVID-19 related practices was $86.4 \%$ (10.66 \pm 2.40$), 85.0 \%$ ( $8.28 \pm 1.94)$, and $97.3 \%(8.34 \pm 1.39)$ respectively. Gender, occupation, and years of experience were associated with knowledge, while years of experience and marital status were associated with attitude and preventive practices. Knowledge score also had significant positive linear associations with both attitudes and practices ( scores toward COVID-19.

Conclusion: Our findings revealed the level of PHCWs preparedness to fight COVID-19 in Rivers State. We suggest that public health education programs on infection prevention and control should be sustained. Furthermore, training should be tailored to meet the peculiarities of the different categories of healthcare workers and years of practice.

\section{Introduction}

The novel Coronavirus disease 2019 (COVID-19) is a new respiratory disease that was reported first in Wuhan, China in December 2019 [1]. it was declared a pandemic by the World Health Organisation (WHO) on 12th March 2020 [2, 3]. The disease as of July 21, 2020, has affected more than 215 countries with $14,684,741$ confirmed cases and 610,110 deaths. The symptoms of the disease include fever, dry cough, fatigue, myalgia, and dyspnea [4].

In Nigeria, the first case of COVID-19 was reported in Lagos on February 27, 2020 [5]. There has been a rapid rise in the number of confirmed cases and deaths. By July 21, 2020, the confirmed cases of COVID19 reported by the National Center for Disease Control (NCDC) stood at 37,225 with 801 deaths and 
15,333 recoveries [6]. Nigeria has the fourth-largest fatality in Africa after South Africa, Egypt, and Algeria [2].

The spread of COVID-19 to many countries has impacted the lives of different populations including healthcare workers. Healthcare workers are affected directly by the pandemic when they contract the disease and indirectly when they have to cope with infected family members. The implication of these is grave for the healthcare system as productive man-hours are lost due to absenteeism from work. Health care workers (HCWs) are also faced with a barrage of challenges like a significant risk of exposure and outbreaks in the workplace, stress, increased workload, and violence [7]. According to NCDC, more than 812 healthcare workers were infected with COVID-19 as of June 2, 2020. [8], this figure is expected to rise as the number of confirmed cases increases. Hence the need for health care workers to adhere to IPC guidelines when attending to clients.

Rivers State is one of the high burden areas of COVID-19 in Nigeria. As of July 21, 2020, the State has recorded 1,535 confirmed cases with 49 deaths [6]. In view of its cosmopolitan nature, this number is expected to rise unless precautionary measures put in place by health institutions and government are adhered to. The State is currently in the community transmission phase and this has the potential to cause fear and panic among the health workers. This may lead to the collapse of the already fragile health system. This may be compounded if the primary health care workers do not have an uninterrupted supply of personal protective equipment (PPE) and elaborate training on infection prevention and control.

According to McEachan and others, the knowledge of disease affects the attitudes and preventive practices of the population in curtailing the spread of the disease [9]. Therefore, this study aimed to assess the preparedness of PHCWs' in term of their knowledge, attitudes, and preventive practices (KAP) for COVID-19 in Rivers State, Nigeria.

\section{Methods}

\section{Study design and population of the study}

A cross-sectional survey study design was conducted among healthcare workers in public primary healthcare facilities (PHFs) across the 23 local government areas (LGAs) of Rivers State, Nigeria.

\section{Sample size and sampling techniques}

The minimum sample size for this study was 363 based on the following assumptions (study population of $6500,95 \%$ confidence level, and $5 \%$ level of precision) using an online sample size calculator. But the number was increased to 460 to accommodate non-response and invalid responses. Twenty questionnaires each was distributed to the 23 LGAs. Four health facilities were selected by simple random sampling from a list of facilities in each LGA, making it a total of 92 PHFs. Similarly, we 
randomly selected five respondents from each of the four facilities, among the healthcare workers at the facilities on the day of the survey

\section{Data collection}

Data for the study was collected from PHCWs across the 23 LGAs of Rivers State from $20^{\text {th }}$ to $29^{\text {th }}$ June 2020 by administering the questionnaire, adapted from the World Health Organisation (WHO) questionnaire on detection, prevention, response, and control of COVID-19 [10]. The questionnaire was divided into two parts: demographics and preparedness. The demographic characteristics were gender, age, marital status, occupation, educational level, local government. area, and years of experience. The preparedness was measured with KAP. The KAP part has 16 questions relating to knowledge, 13 relating to attitude, and 9 questions on the practice of PHCW about COVID-19. A correct answer was assigned 1 point while an incorrect/ I don't know the answer was assigned 0 points. A higher score denoted a good knowledge and lower score a poor knowledge of COVID-19, the same also applied to attitude and practice. Particularly, the scores above $60 \%$ were considered as good KAP.

\section{Statistical analysis}

Data entering and statistical analysis were done using the Statistical Package for Social Science (SPSS) version 25. Descriptive analysis of frequency and percentage were used to report categorical variables, while quantitative variables were reported using mean \pm standard deviation. The association between the responses on KAP and demographic characteristics were tested using Chi-square test. Pearson correlation coefficient was used to evaluate the association that exists among KAP. Statistical significance was evaluated at $\mathrm{P}<0.05$.

\section{Results}

A high response rate of $89.6 \%$ from 460 respondents was obtained. The majority of the respondents were married (74.0\%), female (69.7\%), and belonged to age group 30 to $39(36.4 \%)$ and $40-49(45.4 \%)$ as showed in Table 1. Community health workers and graduate constituted $40.8 \%$ and $56.1 \%$ of the respondents. The main sources of COVID-19 information reported by the respondents were radio (15\%), television (TV) (14\%) and NCDC (14\%), as shown in Figure 1. Over $81 \%(26.0 \%+31.7 \%+23.3 \%)$ of the respondents attested that available information on COVID-19 were at least good, as shown in figure 2 . Similarly, $72 \%(28 \%+27 \%+17 \%)$ of the respondents suggested that the measures adopted by the government, NCDC, and other health institutions in fighting COVID-19 were at least good as depicted in figure 3.

Table 2 reveals the overall knowledge, attitude, and COVID-19 related practices in mean \pm standard deviation, percentages in two groups (poor and good), and correlation statistics. The proportions of primary health workers that have good scores in knowledge, attitude, and COVID-19 related practices are 
$86.4 \%, 85.0 \%$, and $97.3 \%$ respectively. Also, the mean knowledge, attitude, and practices scores were $10.66 \pm 2.40,8.28 \pm 1.94$, and $8.34 \pm 1.39$ in that order. The Pearson correlation test showed a significant positive association between knowledge and attitude $(r=0.35, p<0.05)$, and also between knowledge and practice $(r=0.11, p<0.05)$. But there was no significant association between attitude and practice.

The relationship between the demographic characteristics and mean KAP levels is expressed in Table 3 . We found evidence that gender, occupation, and years of experience were associated with knowledge level $(p<0.05)$. Among these, only years of experience was significantly associated with attitude level ( $p$ $<0.05)$, whereas only marital status was significantly associated with practice level $(p<0.05)$.

Male respondents showed more knowledge compared to their female counterparts (11.28 vs 10.39). Physicians and nurses demonstrated more knowledge about COVID-19 (12.43 and 11.49) respectively than other categories of PHCW. We also found that experienced staff are more knowledgeable and have the right attitude compared with those who are new on the job. For instance, we found evidence of difference between those with $>20$ years and $<5$ years of experience on the job on knowledge ( $11.31 \mathrm{vs}$ 9.75 ) and on attitude (9.08 vs 7.77). There was also a difference in COVID-19 related preventive practices between the single and married respondents ( $8.40 \mathrm{vs} 8.32$ ).

Table 1 Distribution of Primary Healthcare Workers According to their Demographic Characteristics 


\begin{tabular}{|c|c|c|}
\hline Characteristics & Number & Percentage \\
\hline \multicolumn{3}{|l|}{ Gender } \\
\hline Male & 125 & 30.3 \\
\hline Female & 287 & 69.7 \\
\hline \multicolumn{3}{|c|}{ Age as at last birthday } \\
\hline$<30$ & 37 & 9.8 \\
\hline $30-39$ & 138 & 36.4 \\
\hline $40-49$ & 172 & 45.4 \\
\hline$\geq 50$ & 32 & 8.4 \\
\hline Mean \pm SD & $39.47 \pm 7.54$ & \\
\hline \multicolumn{3}{|l|}{ Occupation } \\
\hline Physician & 30 & 7.7 \\
\hline Nurse & 39 & 10.0 \\
\hline Medical Laboratory & 47 & 12.1 \\
\hline Community health & 159 & 40.8 \\
\hline Others & 115 & 29.5 \\
\hline \multicolumn{3}{|l|}{ Educational level } \\
\hline Diploma & 181 & 43.9 \\
\hline Graduate & 231 & 56.1 \\
\hline \multicolumn{3}{|l|}{ Senatorial district } \\
\hline Rivers-east & 143 & 34.7 \\
\hline Rivers-west & 132 & 32.0 \\
\hline Rivers South-east & 137 & 33.3 \\
\hline \multicolumn{3}{|l|}{ Marital status } \\
\hline Single & 107 & 26.0 \\
\hline Married & 305 & 74.0 \\
\hline \multicolumn{3}{|l|}{ Years of experience } \\
\hline$<5$ & 44 & 12.9 \\
\hline $6-10$ & 78 & 22.9 \\
\hline
\end{tabular}




\begin{tabular}{|lll|}
$11-15$ & 101 & 29.7 \\
$16-20$ & 66 & 19.4 \\
$>20$ & 51 & 15.0 \\
\hline
\end{tabular}

Table 2 Number of questions, scores, and level of KAP regarding COVID-19

\begin{tabular}{|lllllllll|}
\hline Levels & $\begin{array}{l}\text { Range of } \\
\text { scores }\end{array}$ & $\begin{array}{l}\text { Total score (Mean } \\
\mathbf{I} \text { SD) }\end{array}$ & \multicolumn{2}{ll}{ Level (\%) } & \multicolumn{2}{l|}{ Correlation } & & \\
\hline Knowledge & $0-15$ & $10.66 \pm 2.40$ & 13.6 & 86.4 & 1 & $0.35^{\star}$ & $0.11^{\star}$ \\
\hline Attitude & $0-11$ & $8.28 \pm 1.94$ & 15.0 & 85.0 & $0.35^{\star}$ & 1 & 0.17 \\
\hline Practice & $0-9$ & $8.34 \pm 1.39$ & 2.7 & 97.3 & $0.11^{\star}$ & 0.17 & 1 \\
\hline
\end{tabular}

*significant at $\mathrm{P}<0.05$

Table 3 Mean score of Primary Healthcare Workers on the level of KAP 


\begin{tabular}{|c|c|c|c|c|c|c|}
\hline \multirow[t]{2}{*}{ Characteristics } & \multicolumn{6}{|c|}{ Mean \pm Standard Deviation } \\
\hline & Knowledge & P-value & Attitude & P-value & Practice & P-value \\
\hline Gender & & 0.03 & & 0.59 & & 0.82 \\
\hline Male & $11.28 \pm 2.19$ & & $8.41 \pm 1.90$ & & $8.43 \pm 1.10$ & \\
\hline Female & $10.39 \pm 2.45$ & & $8.22 \pm 1.96$ & & $8.31 \pm 1.50$ & \\
\hline Age as at last birthday & & 0.87 & & 0.56 & & 0.52 \\
\hline$<30$ & $10.24 \pm 2.29$ & & $8.24 \pm 1.55$ & & $8.30 \pm 1.97$ & \\
\hline $30-39$ & $10.97 \pm 2.31$ & & $8.28 \pm 1.94$ & & $8.41 \pm 1.11$ & \\
\hline $40-49$ & $10.62 \pm 2.49$ & & $8.31 \pm 2.04$ & & $8.24 \pm 1.61$ & \\
\hline$\geq 50$ & $10.47 \pm 1.93$ & & $8.35 \pm 1.93$ & & $8.63 \pm 0.66$ & \\
\hline Occupation & & 0.03 & & 0.77 & & 0.08 \\
\hline Physician & $12.43 \pm 1.45$ & & $8.43 \pm 1.48$ & & $8.50 \pm 0.90$ & \\
\hline Nurse & $11.49 \pm 2.04$ & & $8.64 \pm 1.33$ & & $8.36 \pm 1.55$ & \\
\hline Medical Laboratory & $10.11 \pm 2.78$ & & $8.06 \pm 2.19$ & & $7.85 \pm 2.22$ & \\
\hline Community health & $10.52 \pm 2.32$ & & $8.35 \pm 1.98$ & & $8.36 \pm 1.26$ & \\
\hline Others & $10.48 \pm 2.43$ & & $8.22 \pm 1.94$ & & $8.53 \pm 0.94$ & \\
\hline Educational level & & 0.32 & & 0.53 & & 0.61 \\
\hline Diploma & $10.51 \pm 2.48$ & & $8.38 \pm 2.00$ & & $8.35 \pm 1.44$ & \\
\hline Graduate & $10.77 \pm 2.33$ & & $8.21 \pm 1.90$ & & $8.34 \pm 1.36$ & \\
\hline Senatorial district & & 0.29 & & & & \\
\hline Rivers-east & $10.62 \pm 1.10$ & & $8.41 \pm 1.60$ & 0.16 & $8.48 \pm 0.82$ & 0.28 \\
\hline Rivers-west & $10.74 \pm 2.51$ & & $8.51 \pm 2.02$ & & $8.32 \pm 1.37$ & \\
\hline Rivers South-east & $10.63 \pm 2.67$ & & $7.94 \pm 2.14$ & & $8.23 \pm 1.82$ & \\
\hline Marital status & & 0.07 & & 0.06 & & 0.05 \\
\hline Single & $10.07 \pm 2.55$ & & $7.97 \pm 2.12$ & & $8.40 \pm 0.81$ & \\
\hline Married & $10.87 \pm 2.31$ & & $8.39 \pm 1.87$ & & $8.32 \pm 1.55$ & \\
\hline Years of experience & & 0.00 & & 0.03 & & 0.49 \\
\hline$<5$ & $9.75 \pm 2.87$ & & $7.77 \pm 2.36$ & & $8.50 \pm 1.28$ & \\
\hline 6-10 & $11.35 \pm 1.84$ & & $8.09 \pm 1.89$ & & $8.23 \pm 1.56$ & \\
\hline
\end{tabular}




\begin{tabular}{|llll|}
$11-15$ & $10.67 \pm 2.53$ & $8.56 \pm 1.79$ & $8.48 \pm 1.43$ \\
$16-20$ & $10.39 \pm 2.68$ & $8.48 \pm 1.88$ & $8.24 \pm 1.70$ \\
$>20$ & $11.31 \pm 1.65$ & $9.08 \pm 1.34$ & $8.51 \pm 0.78$ \\
\hline
\end{tabular}

Significant at $\mathrm{P}<0.05$

\section{Discussions}

This study investigated the KAP of public primary healthcare workers towards COVID-19 in Rivers State, Nigeria. This was to ascertain the level of preparedness of primary healthcare workers to maintain services during the pandemic, as the primary level of healthcare is considered the "doorpost" of healthcare delivery. The study participants were predominantly of the female gender, married, and had post-secondary education. This is partly similar to other studies on KAP towards COVID-19 [11-13]. The major sources of information about the virus were radio, TV, and NCDC. This result is comparably the same with studies that showed the main source of information about similar viruses in the Netherlands [14] and Saudi Arabia [15], but contradicted another study in Nigeria that identified work colleagues as the major source of information [11]. This study also suggested that PHCWs are provided with good and adequate information regarding COVID-19 and that adequate measures are in place to combat the pandemic.

The findings on the knowledge scores demonstrated that most of the respondents had sufficient knowledge about COVID-19. This is comparable to earlier studies on KAP towards COVID-19 and similar viruses which revealed a knowledge level of at least $80 \%[12,13,15,16]$. The high knowledge demonstrated by the respondents might be attributed to the level of information available on the virus to the PHCWs, and the fact that most of the respondents were graduates as shown in this study. In addition, gender, occupation, and years of experience are identified as significant factors associated with knowledge level.

Male respondents showed higher knowledge scores than their female counterparts. This result was supported by a previous study on Middle East Respiratory Syndrome (MERS) in Saudi Arabia [15]. Similarly, physicians also showed higher knowledge scores than nurses and other paramedical professionals. This is in agreement with a study on KAP about COVID-19 among health care workers in China [12] and Pakistan [17]. The difference in knowledge scores between physicians and other health staff could be that the scope and quality of infection prevention control training for paramedical workers are low compared to that for physicians [18]. Regarding the association between experience in years and knowledge scores, an increase in years of experience was associated with an increase in mean knowledge scores. This is consistent with an earlier study [15].

The overall positive attitude score for COVID-19 was $85 \%$ under this study, which signified a high positive attitude among the HCWs towards COVID-19. This is supported by an earlier study in Pakistan that showed a high positive attitude among health care professionals towards COVID-19 [17]. This could 
be explained partly by the good knowledge of COVID-19 among HCWs and positive linear correlation between knowledge and attitude scores demonstrated in the study. This is consistent with previous studies $[17,19]$. The positive attitude towards the control and prevention of COVID-19 can also be explained by the actions and stringent control measures adopted by government and relevant agencies in fighting the disease, which include the closing of land and sea borders, airports, and all public spaces, such as open markets and schools [20].The only significant factor associated with attitude was years of experience. Year of experience was significantly related to both knowledge and attitude. This relationship had been reported by earlier studies [15, 21], but contradicted another study in Uganda [13]. Like on knowledge, an increased number of years expended on the job translated to an increase in mean attitude scores.

Furthermore, like knowledge and attitude, the results also revealed that the majority of PHCWs have good practices toward COVID-19 prevention, and this is similar to the findings of Khan et al and Saqlain et al on MERS and COVID-19 respectively $[15,17]$. This result was expected because of the good knowledge, positive attitude of the respondents on COVID-19, and the positive linear correlation between knowledge and practice scores demonstrated in the study. This is partially in agreement with previous on KAP towards COVID-19 among Iranian residents [22]. Marital status was the only significant factor associated with COVID-19 related preventive practices, as the single respondents demonstrated better preventive practices than married participants. This was supported by previous studies on KAP towards COVID-19 in Iran [22] and Bangladeshi [23].

\section{Conclusion}

The very first step in public health interventions is awareness of the disease or problem. COVID-19 is considered a public health problem across the countries of the world and the number of cases is rapidly increasing in Nigeria. Therefore, the KAP as a measure of preparedness of the healthcare workers at the primary health facilities is of paramount importance. The results of this study demonstrated that the health workers at the primary level of care have sufficient knowledge, a positive attitude, and good preventive practices towards COVID-19, suggesting high level of preparedness to fight COVID-19 in Rivers State. We found evidence of a number of factors that are associated with knowledge level, attitude, and practice. There were associations between the knowledge levels of the PHCWs and their attitude and preventive practice. Based on these findings, we suggest that public health education programs should be sustained. Furthermore, training should be tailored to meet the peculiarities of the different categories of primary healthcare workers and years of practice.

\section{Declarations}

\section{Acknowledgments}

We thank all the PHCWs that voluntarily participated in the survey. We particularly thank the Medical Officers of Health (MOH) and the Monitoring and Evaluation Officers (M\&E) across the 23 LGA of Rivers 
State for their contribution towards the survey.

\section{Ethical Issues}

The study was approved by the Rivers State Health Research Ethics Committee (RSHMB/RSHREC/11.20/VOL.8/063). The questionnaire was administered with strict adherence to the standard instructions by the NCDC and the Ministry of Health, such as physical distancing, wearing of face masks and hand gloves. The written consent of each respondent was obtained before their participation.

\section{Competing Interests}

There were no competing interests to be declared

\section{Funding Sources}

There was no funding received for this study

\section{References}

1. World Health Organization (WHO). Coronavirus disease 2019 (COVID-19) Situation Report-94. http://www.who.int/docs/default-source/coronaviruse/situation reports/20200423-sitrep-94-covid19.pdf?sfvrsn=b8304bf0_4. Accessed July 21, 2020.

2. European Centre for Disease Prevention and Control published July $21 \mathrm{st}$. 2020. Available from: http://www.ecdc.europa.eu/en/geographical-distribution-2019-ncov-cases. Accessed July 21, 2020.

3. World Health Organization. WHO announces COVID-19 outbreak a Pandemic. http://www.euro.who.int/en/health-topics/health-emergencies/coronaviruscovid19/news/news/2020/3/who-announces-covid-19-outbreak-a-pandemic Accessed July 21, 2020.

4. Zhong B-L, Luo W, Li H-M, et al. Knowledge, attitudes, and practices towards COVID-19 among Chinese residents during the rapid rise period of the COVID-19 outbreak: a quick online crosssectional survey. Intl J Bio Sci. 2020;16(10):1745-1752.

5. Nigeria Center for Disease Control. First case of coronavirus confirmed in Nigeria. https//www.ncdc.gov.ng/news/227/first-case-of-corona-virus-disease-confirmed-in-nigeria (Accessed July 21, 2020)

6. Nigeria Center for Disease Control Website http://www.covid19.ncdc.gov.ng (Accessed July 21, 2020) 
7. Dai Y, Hu G, Xiong H, Qiu H, Yuan X. Psychological impact of the coronavirus disease 2019 (COVID19) outbreak on healthcare workers in China. https://doi.org/10.1101/2020.03.03.20030874. Published 2020. Accessed May 20, 2020

8. Punch Newspaper. 812 healthcare workers infected with COVID-19. https://www.healthwise.punchng.com/812-healthcare-workers-infected-with-covid-19-ncdc. Published June 3, 2020. Accessed July 16, 2020.

9. McEachan R, Taylor N, Harrison R, Lawton R, Gardner 2, Conner M.., Meta-Analysis of the Reasoned Action Approach (RAA) to Understanding Health Behaviors. Ann Behav Med, 2016. 50(4): 592-612.

10. World Health Organization. Emerging respiratory viruses, including COVID-19: methods for detection, prevention, response, and control. https://openwho.org/courses/introductionto-ncov. Published 2020. Accessed June 11, 2020.

11. Ogolodom MP, Mbaba AN, Alazigha N, et al. Knowledge, Attitudes and Fears of HealthCare Workers towards the Corona Virus Disease (COVID-19) Pandemic in South-South, Nigeria. Health Sci J. 2020 Sp. Iss 1: 002.

12. Zhou M, Tang F, Wang Y, et al. Knowledge, attitude and practice regarding COVID-19 among health care workers in Henan, China, Journal of Hospital Infection Website. https://doi.org/10.1016/j.jhin.2020.04.01s2. Published 2020. Accessed July 2, 2020.

13. Olum R, Chekwech G, Wekha G, Nassozi DR and Bongomin F. Coronavirus Disease-2019: Knowledge, Attitude, and Practices of Health Care Workers at Makerere University Teaching Hospitals, Uganda. Front. Public Health 8:181. doi: 10.3389/fpubh.2020.00181

14. Brug J, Aro AR, Oenema A, De Zwart O, Richardus JH, Bishop GD: SARS risk perception, knowledge, precautions, and information sources, the Netherlands. Emerg Infect Dis 2004; 10:1486-1489

15. Khan MU, Shah S, Ahmad A, Fatokun O. Knowledge and attitude of healthcare workers about middle east respiratory syndrome in multispecialty hospitals of Qassim, Saudi Arabia. BMC Public Health 2014; 14:1281. doi:10.1186/1471-2458-14-1281

16. Azlan AA, Hamzah MR, Sern TJ, Ayub SH, Mohamad E. Public knowledge, attitudes and practices towards COVID-19: A cross-sectional study in Malaysia. PLoS ONE, 2020; 15(5): e0233668. https://doi.org/10.1371/journal.pone.0233668

17. Saqlain M, Munir MM, Rehman S, Gulzar A, Naz S, Ahmed Z, et al. Knowledge, attitude, practice and perceived barriers among healthcare professionals regarding COVID-19: A Cross-sectional survey from Pakistan. medRxiv Preprint doi: https://doi.org/10.1101/2020.04.13.20063198. Accessed July 20, 2020.

18. Ngwa $\mathrm{CH}$, Ngoh EA , Cumber SN. Assessment of the knowledge, attitude and practice of health care workers in Fako Division on post exposure prophylaxis to blood borne viruses: a hospital based cross-sectional study. Pan African Medical Journal. 2018; 31:108. doi:10.11604/pamj.2018.31.108.15658

19. Giao H, Thi N, Han N, et al. Knowledge and attitude toward COVID-19 among healthcare workers at Knowledge and attitude toward COVID-19 among healthcare workers at District 2 Hospital, Ho Chi 
Minh City. Asian Pac J Trop Med. 2020;13: 1-6. doi:10.4103/1995-7645.280396

20. Edet CK, Wegbom Al, Kiri VA. Knowledge, Attitude and Practice of Clients towards COVID-19 at Primary Healthcare Facilities in Rivers State, Nigeria. Research Square, Preprints 2020: DOI: https://doi.org/10.21203/rs.3.rs-40966/v1. Accessed July 20, 2020.

21. Tam DKP, Lee S, Lee SS: Impact of SARS on avian influenza preparedness in healthcare workers. Infection 2007; 35:320-325.

22. Erfani A, Shahriarirad R, Ranjbar K, Mirahmadizadeh A, Moghadami M. Knowledge, Attitude and Practice toward the Novel Coronavirus (COVID-19) Outbreak: A Population-Based Survey in Iran. [Preprint]. Bull World Health Organ. E-pub: 30 March 2020. doi:

http://dx.doi.org/10.2471/BLT.20.256651. Accessed June 28, 2020

23. Rahman A, Sathi NJ. Knowledge, Attitude, and Preventive Practices toward COVID-19 among Bangladeshi Internet Users. Electron J Gen Med. 2020;17(5):em245. https://doi.org/10.29333/ejgm/8223

\section{Figures}

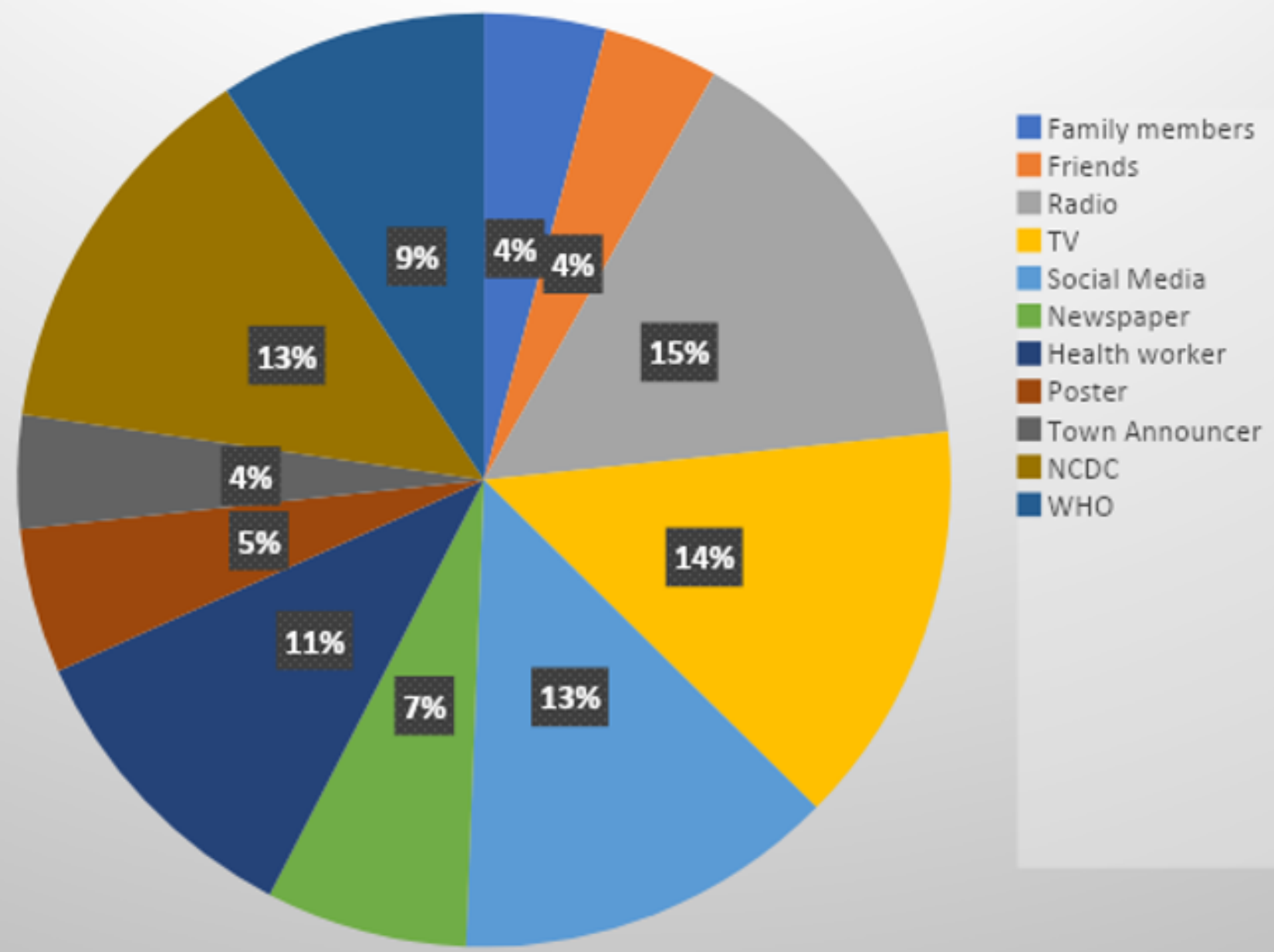


Source of information for COVID-19 by PHCW

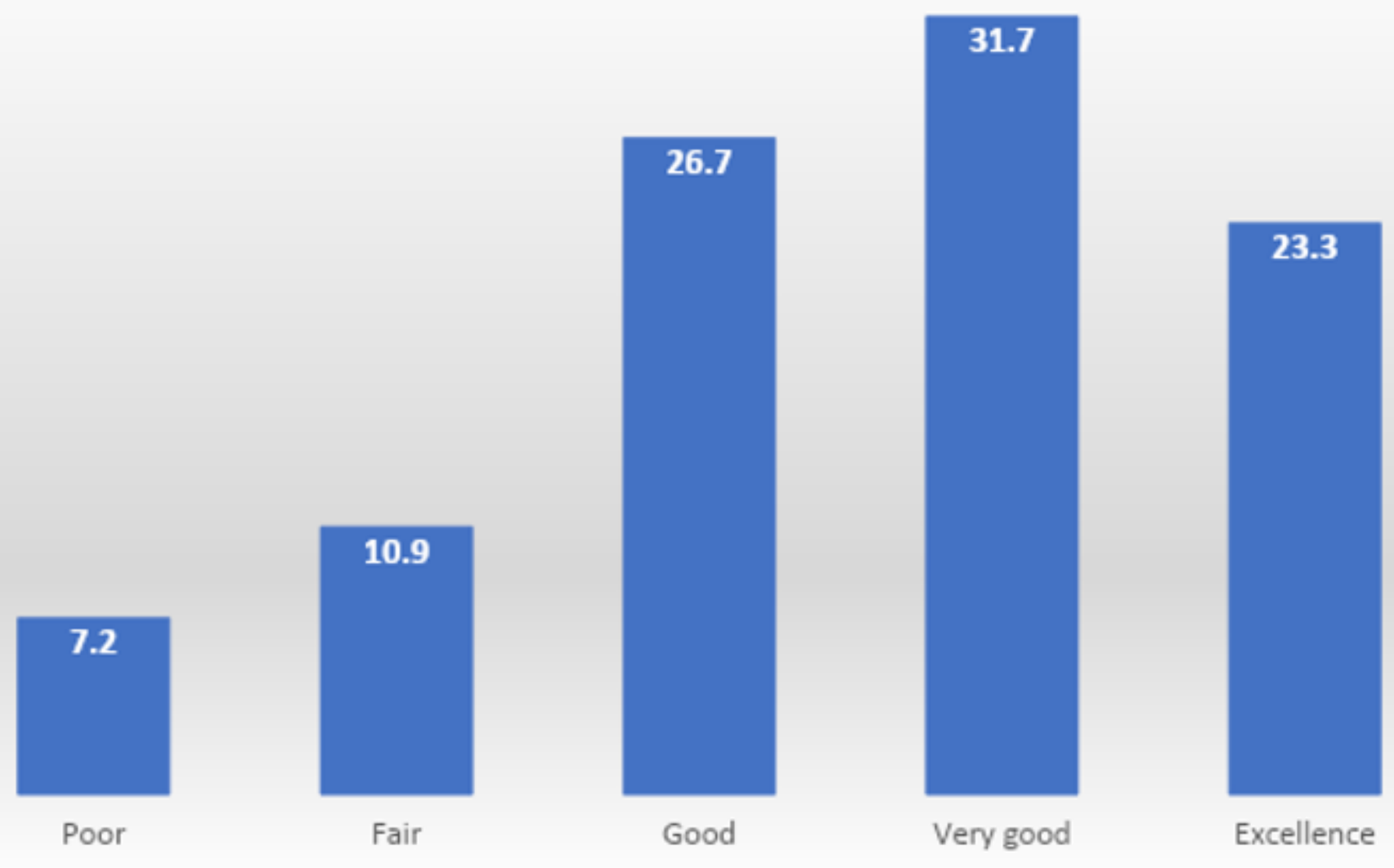

Figure 2

Information available on COVID-19 by PHCW 


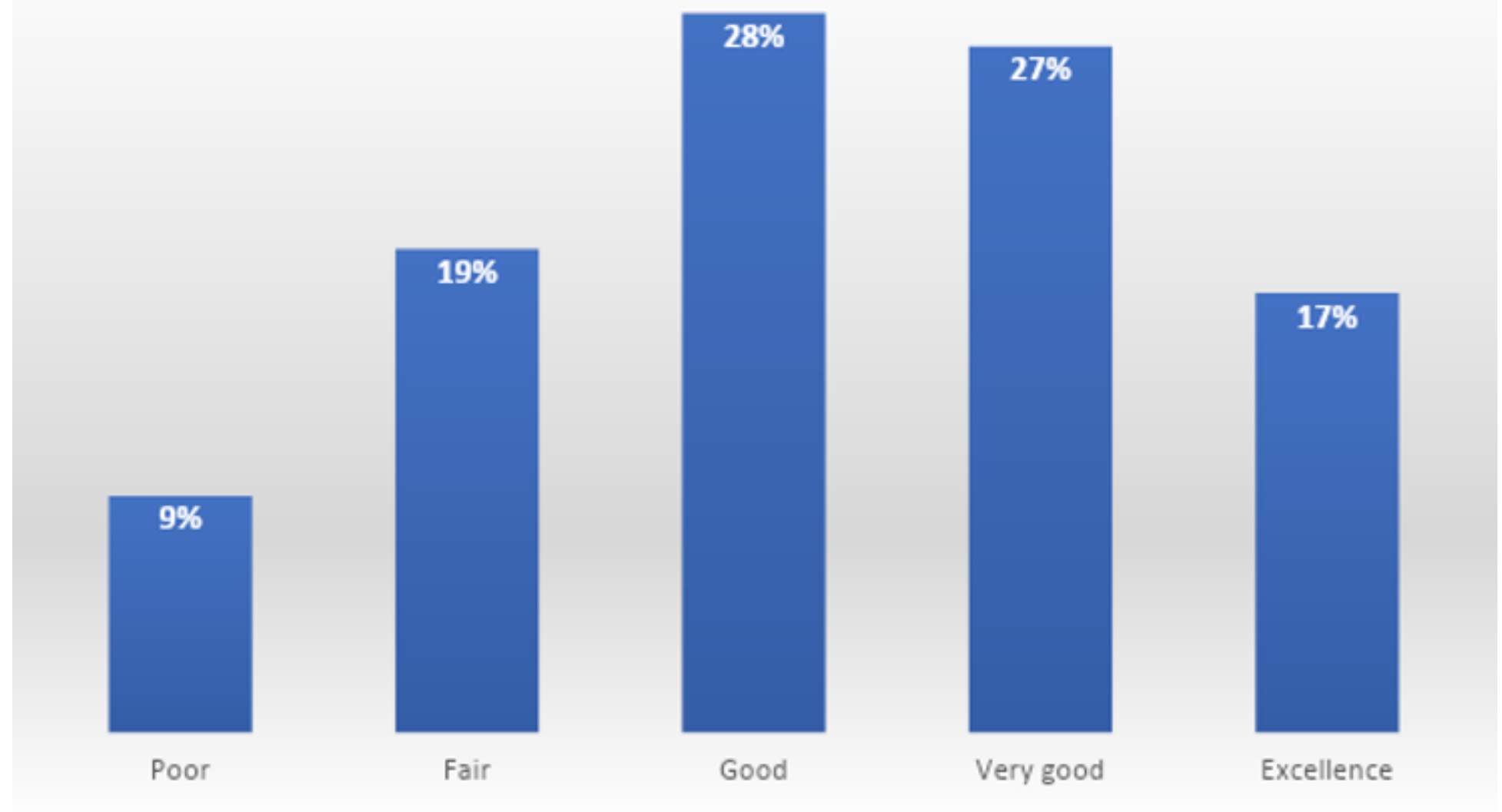

Figure 3

Measures adopted by the government, NCDC, and other health institutions in fighting COVID-19 